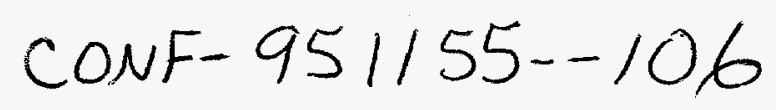

Note: This is a preprint of a paper being submitted for publication. Contents of this paper should not be quoted nor referred to without permission of the author(s).

To be submitted to 95 Fall MRS Proceedings, Symposium A.

\title{
Nanocrystals and Quantum Dots Formed by High-Dose Ion Implantation
}

\author{
C. W. White, J. D. Budài, J. G. Zhu, and S. P. Withrow \\ Oak Ridge National Laboratory \\ Oak Ridge, TN \\ D. M. Hembree \\ The Oak Ridge Y-12 Plant \\ Oak Ridge, TN
}
Fisk University
Nashville, TN

\begin{abstract}
"The submitted manuscript has been authored by a contractor of the U.S. Govermment under contract No. DE-ACOS84OR21400. Accordingly, the US. Government retuins a nonexclusive. Government retains nonexclusive, royalty-free license to publish of reproduce the published form of this contribution, or allow others to do so, for
\end{abstract} U.S. Government purposes."

D. O. Henderson, A. Ueda, Y. S. Tung, and R. Mu

Prepared by the

Oak Ridge National Laboratory

Oak Ridge, Tennessee 37831

managed by

LOCKHEED MARTIN ENERGY RESEARCH CORP.

for the

U.S. DEPARTMENT OF ENERGY

under contract DE-ACO5-960R22464

\section{DISTRIBUTION OF THIS DOCUMENT IS UNLIMITED}

\section{January 1996}

\section{DISCLAIMER}

This report was prepared as an account of work sponsored by an agency of the United States Government. Neither the United States Government nor any agency thereof, nor any of their employees, makes any warranty, express or implied, or assumès any legal liability or responsibility for the accuracy, completeness, or usefulness of any information, apparatus, product, or process disclosed, or represents that its use would not infringe privately owned rights. Reference herein to any specific commercial product, process, or service by trade name, trademark, manufacturer, or otherwise does not necessarily constitute or imply its endorsement, recommendation, or favoring by the United States Government or any agency thereof. The views and opinions of authors expressed herein do not necessarily state or reflect those of the United States Government or any agency thereof. 


\title{
NANOCRYSTALS AND QUANTUM DOTS FORMED \\ BY HIGH-DOSE ION IMPLANTATION
}

\author{
C. W. WHITE,* J. D. BUDAI,* J. G. ZHU,* S. P. WITHROW,* D. M. HEMBREE,** \\ D. O. HENDERSON, ${ }^{\dagger}$ A. UEDA, ${ }^{\dagger}$ Y. S. TUNG, ${ }^{\dagger}$ and R. MU ${ }^{\dagger}$ \\ * Oak Ridge National Laboratory, Oak Ridge, Tenn. \\ **The Oak Ridge Y-12 Plant, Oak Ridge, Tenn. \\ †Fisk University, Nashville, Tenn.
}

\begin{abstract}
Ion implantation and thermal annealing have been used to produce a wide range of nanocrystals and quantum dots in amorphous $\left(\mathrm{SiO}_{2}\right)$ and crystalline $\left(\mathrm{Al}_{2} \mathrm{O}_{3}\right)$ matrices. Nanocrystals of metals ( $\mathrm{Au}$ ), elemental semiconductors ( $\mathrm{Si}$ and $\mathrm{Ge}$ ), and even compound semiconductors ( $\mathrm{SiGe}, \mathrm{CdSe}, \mathrm{CdS}$ ) have been produced. In amophous matrices, the nanocrystals are randomly oriented, but in crystalline matrices they are three dimensionally aligned. Evidence for photoluminescence and quantum confinement effects are presented.
\end{abstract}

\section{INTRODUCTION}

Nanocrystals and quantum dots have attracted considerable interest because of their unique

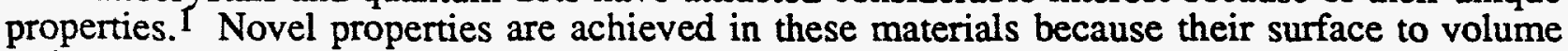
ratios are enormous, and their energy levels can be shifted considerably due to quantum confinement effects which occur when dimensions of crystallites are reduced to a size comparable to their excitonic radius. Such size reduction leads to unusual optical, electrical, mechanical, and physical properties. Many methods are being explored to synthesize nanocrystals and quantum dots. Ion implantation is ideally suited to create high densities of nanocrystals in the near-surface region of a number of matrices, and this has been recognized and exploited by a number of groups. Implantation is used to create a supersaturated solution in the near-surface region and thermal annealing (or implantation at elevated temperature) leads to precipitation and the formation of nanocrystals. Implantation of $\mathrm{Au}^{2-4}$ and $\mathrm{Cu}^{5,6}$ into fused silica has been used to form metallic nanocrystals which exhibit large optical nonlinearities. The implantation of $\mathrm{Ge}$ or $\mathrm{Si}$ into $\mathrm{SiO}_{2}$ gives rise to the formation of elemental semiconductor nanocrystals which can exhibit strong photoluminescence (PL) in the visible and near IR region. ${ }^{7-12}$ Oriented nanocrystals of $\mathrm{Si}$ and $\mathrm{Ge}$ in $\alpha-\mathrm{Al}_{2} \mathrm{O}_{3}$ have been produced by ion implantation. 13 Finally, by implanting various combinations of ions, compound semiconductor nanocrystals 14 have been produced in $\mathrm{SiO}_{2}$ and $\mathrm{Al}_{2} \mathrm{O}_{3}$ and metal alloy nanocrystals 15 have been formed in $\mathrm{SiO}_{2}$. Compound semiconductor nanocrystals are expected to exhibit strong optical nonlinearities and a fast response time. ${ }^{16}$ Metallic nanocrystals in glass also exhibit large optical nonlinearities and a response time measured in picosecond. 17

In this paper, we present results on the synthesis, characteristics, and properties of nanocrystalline composites formed by ion implantation. The results will demonstrate that nanocrystals can be formed in a variety of matrices. When formed by ion implantation, the nanocrystals are encapsulated in the matrix. In many cases, these nanocrystals have not been incorporated into those matrices by other techniques due to sensitivity to oxidizing conditions or the very high melting temperatures of the matrix material. Ion implantation may be the simplest technique available to embed nanocrystals in some of these materials. With ion implantation, metallic, elemental semiconductor, and even compound semiconductor nanocrystals can be embedded into a number of matrices.

\section{EXPERIMENTAL CONDITIONS}

Ions were implanted into fused silica (Corning 7940), thermally oxidized silicon wafers $\left(\mathrm{SiO}_{2} / \mathrm{Si}\right)$, or $\alpha-\mathrm{Al}_{2} \mathrm{O}_{3}(0001)$ to doses of $\sim 1 \times 10^{17} / \mathrm{cm}^{2}$ and at energies chosen to give a projected range of $100 \mathrm{~nm}$ or greater. Various combinations of ions were implanted at energies 
chosen to give an overlap of the individual profiles in order to form compounds or alloys. Following implantation, samples were annealed in flowing $\mathrm{Ar}+4 \% \mathrm{H}_{2}$ to induce precipitation and nanocrystal formation. Characterization was carried out using a variety of techniques including x-ray diffraction, Rutherford backscattering ion channeling ( $2.3 \mathrm{MeV} \mathrm{He}$ ions), crosssection transmission electron microscopy, Raman spectroscopy, and various types of optical measurements (absorption, PL, infrared reflectivity).

\section{RESULTS}

Figure 1 shows the high density of Au nanocrystals that can be formed in fused silica by the implantation of $\mathrm{Au}(2.75 \mathrm{MeV})$ with the substrate at a temperature of $600^{\circ} \mathrm{C}$. Individual nanocrystals are spherical crystals which are oriented at random relative to each other The average diameter in this case is $-130 \AA$. The size and size distribution can be changed considerably by changes in the implantation and annealing conditions as shown in Fig. 2 . The average size can be changed from $-25 \AA$ to $-125 \AA$ by changing the implantation or annealing conditions as indicated. An unexpected finding is that $\mathrm{Au}$ nanocrystals in $\mathrm{SiO}_{2}$ produced by annealing in a reducing environment $\left(\mathrm{Ar}+4 \% \mathrm{H}_{2}\right)$ are considerably smaller than those produced by annealing in an oxidizing environment.

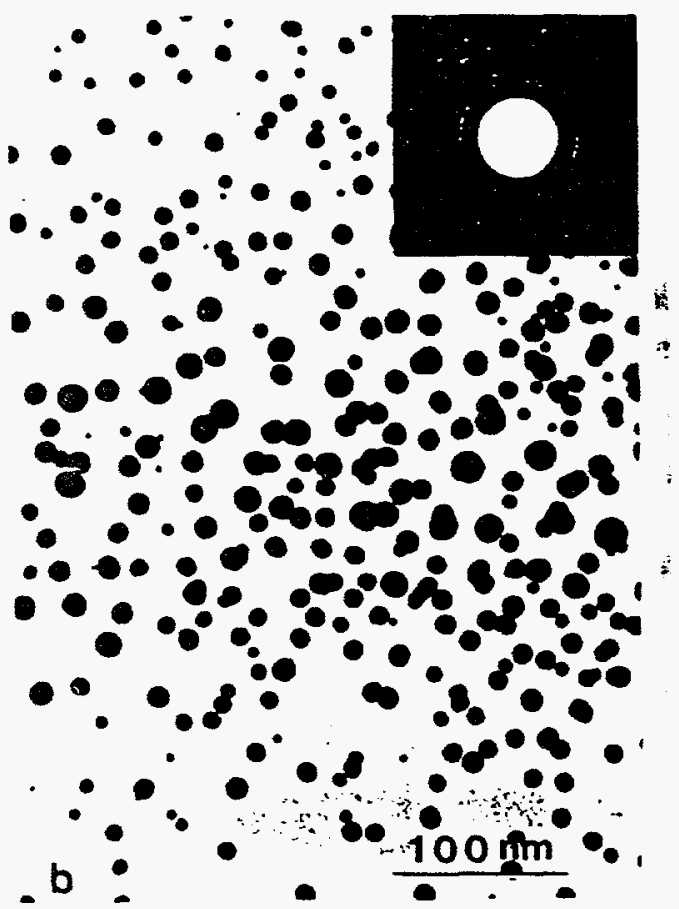

Fig. 1. Cross section micrograph showing $\mathrm{Au}$ nanocrystals formed in fused silica by the implantation of $\mathrm{Au}\left(2.75 \mathrm{MeV}, 1.5 \times 10^{11} / \mathrm{cm}^{2}\right)$ at a temperature of $600^{\circ} \mathrm{C}$.

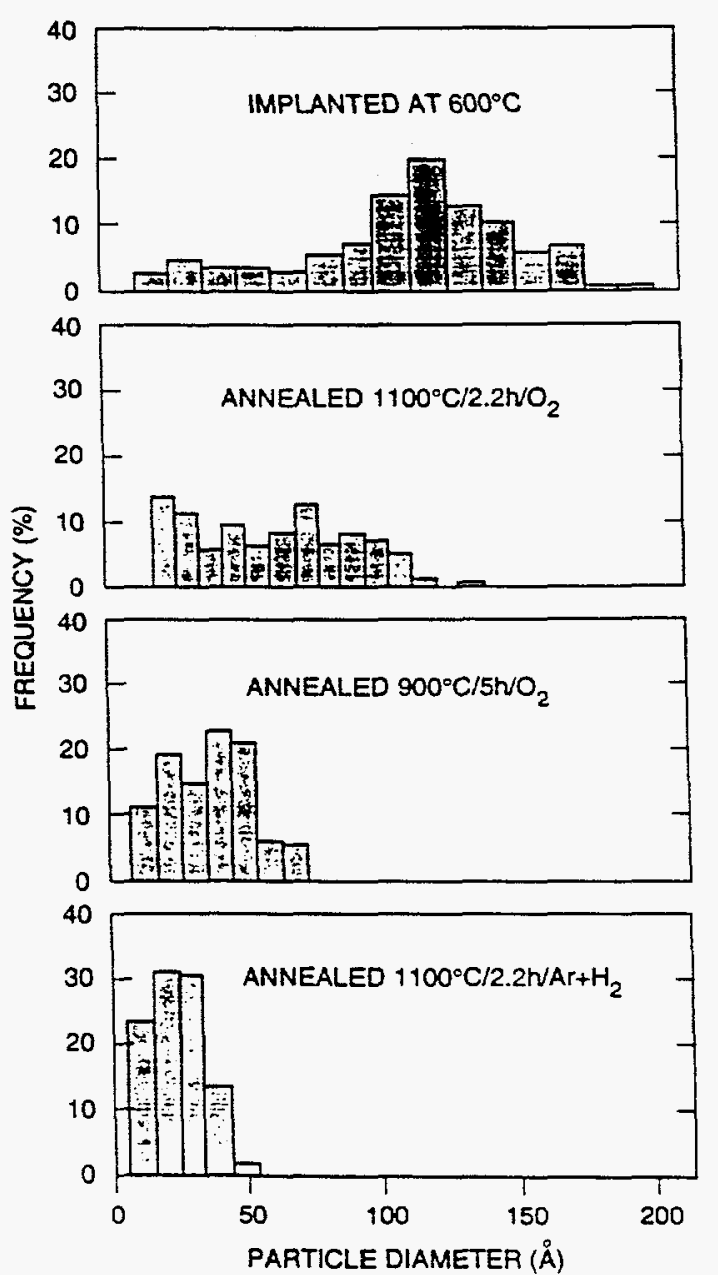

Fig. 2. Size distributions for $\mathrm{Au}$ nanocrystals in fused silica following Au $\left(2.75 \mathrm{MeV}, 1.5 \times 10^{17} / \mathrm{cm}^{2}\right)$ implantation. The top distribution was measured following implantation at $600^{\circ} \mathrm{C}$. The other three distributions were measured after annealing samples implanted at room temperature. 
The presence of these Au nanocrystals in the near-surface region gives rise to a refractive index which is dependent on light intensity and a very fast response time, which makes these materials interesting candidates for nonlinear optical applications. ${ }^{2}$ The nonlinear index depends on the volume fraction occupied by the nanocrystals and is of the order of $\sim 10^{-9} \mathrm{~cm}^{2} /$ watt (near the plasmon resonance wavelength) for volume fractions of $\sim 10 \%$, which is easily achieved by implantation. 3 The nonlinear response time for Au nanocrystals in glass is in the picosecond time regime. 17

$\mathrm{Si}$ and $\mathrm{Ge}$ nanocrystals can be synthesized in both $\mathrm{SiO}_{2}{ }^{7-12}$ and $\mathrm{Al}_{2} \mathrm{O}_{3} .{ }^{13}$ In $\mathrm{SiO}_{2}$, the nanoparticles are very small, and their presence at high densities can give rise to strong PL. Figure 3 compares PL from porous Si with that arising from the implantation of $\mathrm{Si}(400 \mathrm{keV}$, $6 \times 10^{17} / \mathrm{cm}^{2}$ ) into $\mathrm{SiO}_{2}$ followed by annealing at $1100^{\circ} \mathrm{C}$ to form silicon nanocrystals. The PL from the sample containing the silicon nanocrystals is comparable in intensity to that measured from porous silicon, but shifted in wavelength. PL from the sample with silicon nanocrystals is very stable with time, while that from porous $\mathrm{Si}$ exhibits considerable variation from spot to spot and as a function of exposure time to the excitation beam. The Si nanocrystals which give rise to the PL in Fig. 3 are very small, and examples are shown in the cross-section TEM micrograph of Fig. 4. The average diameter is $\sim 4 \mathrm{~nm}$, with almost no particles being in excess of $8 \mathrm{~nm}$ diameter. The wavelength of PL can be shifted slightly to higher energies by reducing the dose or by reducing the annealing time, both of which are expected to lead to smaller nanocrystals. An example of the dose dependence is shown in Fig. 5 where the PL peak intensity can be shifted from $\sim 7500 \AA$ to $\sim 6900 \AA$ by reducing the dose from $6 \times 10^{17} / \mathrm{cm}^{2}$ to $3 \times 10^{16} / \mathrm{cm}^{2}$ (at $400 \mathrm{keV}$ energy). The shift to higher energy with decreasing particle size is consistent with that expected if the PL originates from quantum confined excitons, but the magnitude of the shift is considerably less than predictions of the increase in bandgap with decreasing particle size. Such a discrepancy suggests that defect states in the interface between the nanocrystal and the oxide matrix may play an important role in the PL from silicon nanocrystals.

Compound semiconductors and alloy nanocrystals can be formed by sequential implantation of various combinations of ions followed by annealing. One example is shown by the Raman spectra of Fig. 6 taken following the implantation of equal doses $\left(3 \times 10^{17} / \mathrm{cm}^{2}\right)$ of $\mathrm{Ge}(500 \mathrm{keV})$ and $\mathrm{Si}(215 \mathrm{keV})$ into $\mathrm{SiO}_{2} / \mathrm{Si}$ and annealed at $1100^{\circ} \mathrm{C} / 1 \mathrm{~h}$. In the $\mathrm{SiO}_{2} / \mathrm{Si}$ sample, strong Raman lines at 285,405 , and $485 \mathrm{~cm}^{-1}$ are observed following the implantation of $\mathrm{Ge}$ and $\mathrm{Si}$. (The sharp Raman line at $-520 \mathrm{~cm}^{-1}$ arises from the underlying Si substrate.) These lines indicate Ge-Ge, $\mathrm{Si}-\mathrm{Ge}$, and $\mathrm{Si}-\mathrm{Si}$ bonds in $\mathrm{SiGe}$. Their positions and relative intensities are comparable to those seen from a $\mathrm{Si}_{x} \mathrm{Ge}_{1-x}(x=0.48)$ bulk alloy standard. This demonstrates the formation of the compound $\mathrm{SiGe}$ and transmission electron microscope results (not shown) show that nanocrystal diameters up to several hundred angstroms are produced.

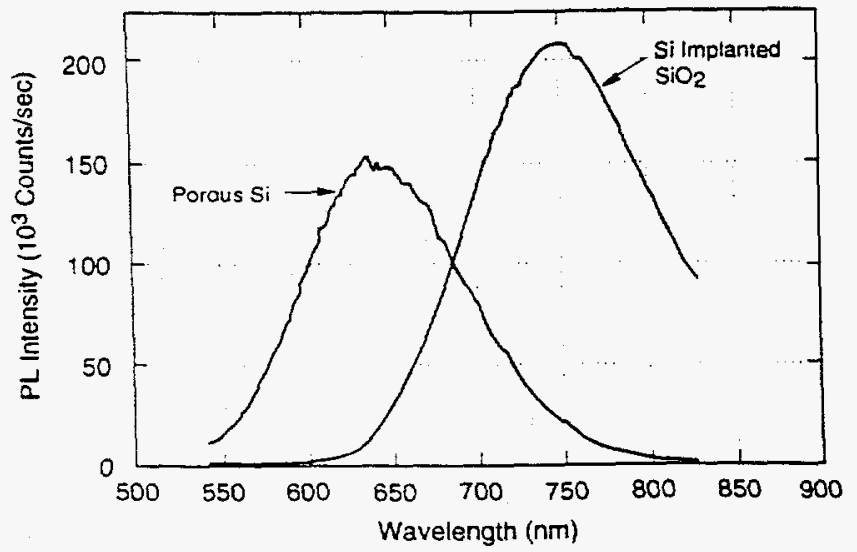

Fig. 3. PL arising from porous silicon and from $\mathrm{SiO}_{2}$ implanted by $\mathrm{Si}(400 \mathrm{keV}$, $6 \times 10^{17} / \mathrm{cm}^{2}$, room temperature) and subsequently annealed at $1100^{\circ} \mathrm{C} / 1 \mathrm{~h}$. PL was excited by radiation at $514.5 \mathrm{~nm}$.

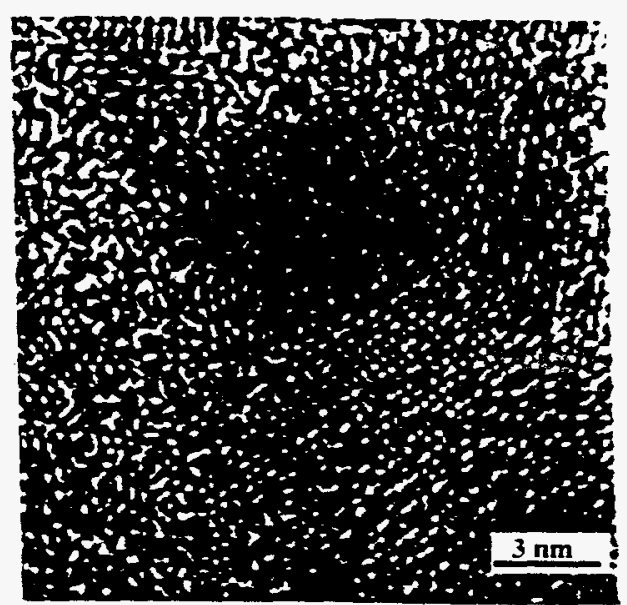

Fig. 4. High resolution cross section micrograpn showing Si nanocrystals formed by implantation of $\mathrm{Si}\left(400 \mathrm{keV}, 6 \times 10^{17} / \mathrm{cm}^{2}\right.$, room temperature) into $\mathrm{SiO}_{2}$, followed by annealing $\left(1100^{\circ} \mathrm{C} / 1 \mathrm{~h}\right)$. 


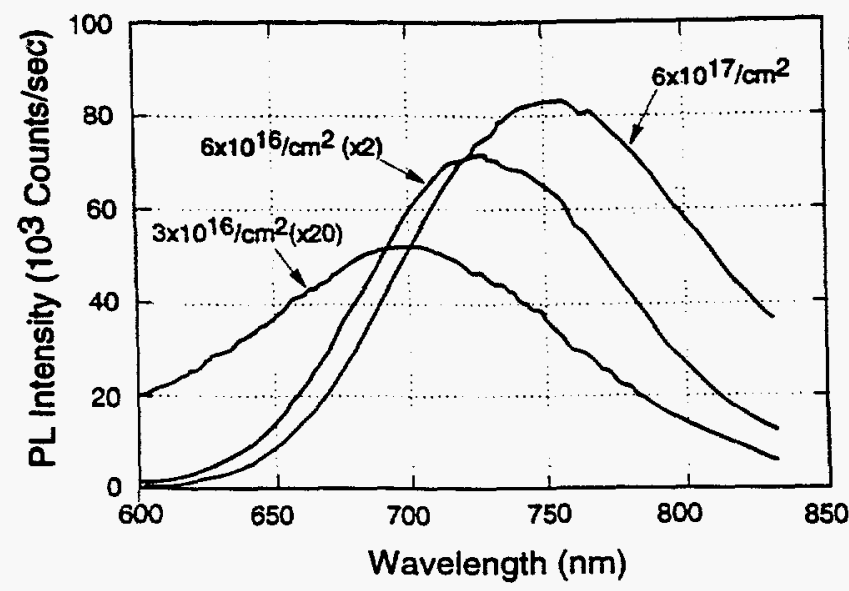

Fig. 5. PL arising from Si ( $400 \mathrm{keV}$ ) implanted $\mathrm{SiO}_{2}$. Decreasing doses were used to produce smaller nanocrystals. Samples were annealed at $1100^{\circ} \mathrm{C} / 1 \mathrm{~h}$.

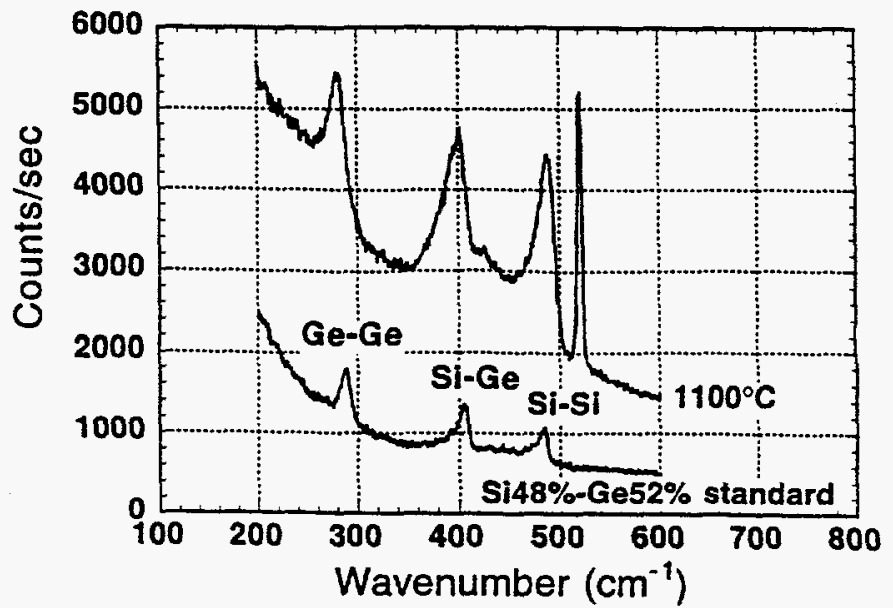

Fig. 6. Raman spectra from $\mathrm{SiGe}$ nanocrystals in $\mathrm{SiO}_{2} / \mathrm{Si}$. Results from a $\mathrm{Si}_{x} \mathrm{Ge}_{1-x}(x=0.48)$ bulk alloy are shown for comparison.

Both III-V compound semiconductor and II-VI compound semiconductor nanocrystals have been produced in $\mathrm{SiO}_{2}$ by sequential implantation. This is demonstrated by the $\mathrm{X}$-ray diffraction results of Fig. 7 for several different II-VI compound semiconductor nanocrystals. Following implantation and annealing, the X-ray diffraction results reveal the presence of the hexagonal structure of CdSe (in the case of $\mathrm{Cd}+\mathrm{Se}$ implants) and the hexagonal structure of CdS (in the case of $\mathrm{Cd}+\mathrm{S}$ implants). For the case of $\mathrm{Cd}+0.5 \mathrm{Se}+0.5 \mathrm{~S}$, the $\mathrm{X}$-ray diffraction peaks are intermediate between those of $\mathrm{CdSe}$ and $\mathrm{CdS}$. This is strong evidence that the mixed chalcogenide $\mathrm{Cd}_{1} \mathrm{Se}_{0.5} \mathrm{~S}_{0.5}$ has been formed by the sequential implantation of three ions. This evidence is supported by Raman measurements (not shown) which clearly show the formation of a mixed chalcogenide. This is the first report of a triatomic compound formed by sequential implantation.

Figure 8 shows the individual CdSe nanocrystals formed by sequential implantation (Fig. 8a) and the measured size distribution for the nanocrystals (Fig. 8b). The average diameter is $\sim 60 \AA$ following annealing at $1000^{\circ} \mathrm{C}$. This size is slightly smaller than the bulk exciton diameter $(\sim 90 \AA)$ and therefore these nanocrystals should show effects of quantum confinement. This is demonstrated in Fig. 9 which shows measured optical absorption results following implantation of $\mathrm{Cd}$ and $\mathrm{Se}$ (doses of $1 \times 10^{17} / \mathrm{cm}^{2}$ ). Absorption results are shown in the as-implanted state and after annealing $\left(1000^{\circ} \mathrm{C} / 1 \mathrm{~h}\right)$. Following annealing, weak and broad absorption features are measured at $\sim 6370 \AA$ and $\sim 5310 \AA$. These features are blue shifted with respect to the absorption edge of the bulk material $(\sim 7130 \AA)$, and this shift is believed to be due to quantum confinement of excitons.

In addition to producing nanocrystals and quantum dots in $\mathrm{SiO}_{2}$ by sequential implantation, these techniques can also be used to synthesize nanocrystals in crystalline matrices such as $\mathrm{Al}_{2} \mathrm{O}_{3}$. To date, we $11,13,18$ have produced a wide range of nanocrystals in $\mathrm{Al}_{2} \mathrm{O}_{3}$ by ion implantation including $\mathrm{Si}, \mathrm{Ge}, \mathrm{GaAs}, \mathrm{SiGe}, \mathrm{CdSe}$, and $\mathrm{CdS}$. Figure 10 shows $\mathrm{X}$-ray diffraction results for the case of $\mathrm{CdSe}$ nanocrystals in (0001) $\mathrm{Al}_{2} \mathrm{O}_{3}$. The $\theta-2 \theta$ scan along the $c$ axis of $\mathrm{Al}_{2} \mathrm{O}_{3}$ shows the expected diffraction from the matrix. In addition, there are a multitude of diffraction peaks which have been identified as arising from CdSe. These nanocrystals can exist in either an hexagonal or a cubic structure. Detailed analysis of the $\mathrm{X}$-ray results show that if implantation is performed at elevated temperature, the hexagonal phase of CdSe is favored. (By contrast, if the implant is performed at room temperature, formation of the cubic phase of CdSe is favored.) In Fig. 10, the $\theta-2 \theta$ results show that most of the hexagonal CdSe nanoparticles are oriented with their $(002)$ planes parallel to the $(0001)$ planes of $\mathrm{Al}_{2} \mathrm{O}_{3}$. These $(002)$ oriented hexagonal CdSe nanoparticles also exhibit strong in-plane alignment as demonstrated by the $\phi$ scans through the (103) reflections. This scan is sixfold symmetric as expected for the (002) oriented hexagonal $\mathrm{CdSe}$ nanoparticles. Therefore, the CdSe nanocrystals are three dimensionally aligned with the crystalline $\mathrm{Al}_{2} \mathrm{O}_{3}$ matrix. 
CdSe nanoparticles in $\mathrm{Al}_{2} \mathrm{O}_{3}$ also show evidence for quantum confinement. This is demonstrated in Fig. 11 which compares band edge PL from hexagonal CdSe nanocrystals in $\mathrm{Al}_{2} \mathrm{O}_{3}$ with that arising from a bulk CdSe standard. The PL from the CdSe nanocrystals is blue shifted by $\sim 0.1 \mathrm{eV}$ relative to that from bulk CdSe, presumably as a result of quantum confinement.

In conclusion, sequential implantation followed by annealing has been used to synthesize a wide range of compound semiconductor nanocrystals. Table I provides a list of the compound semiconductor nanocrystals which have been produced in $\mathrm{SiO}_{2}, \mathrm{Al}_{2} \mathrm{O}_{3}$, and single-crystal $\mathrm{Si}$. In most cases, positive identification is obtained from diffraction measurements. Results achieved for $\mathrm{GaAs}$ and $\mathrm{GaP}$ in silicon are very recent and are reported elsewhere, 19 but they demonstrate that nanocrystals can be formed even though one of the constituents (As or P) is highly soluble in the silicon matrix. Results shown in Table I demonstrate that a wide range of alloys and compounds can be formed in several matrices by sequential implantation. As discussed elsewhere, 19 the free energy of the desired compound relative to that of other possible compounds or solid solutions is the dominant factor in determining whether the desired compound will form (assuming no kinetic limitations). In previous work on compound formation, the matrix material was one of the major constituents of the compound. Results presented here demonstrate that compounds can be formed by implanting both (or more) constituents. Therefore, sequential implantation should greatly extend the use of ion beam synthesis for compound formation in these and many other matrices.

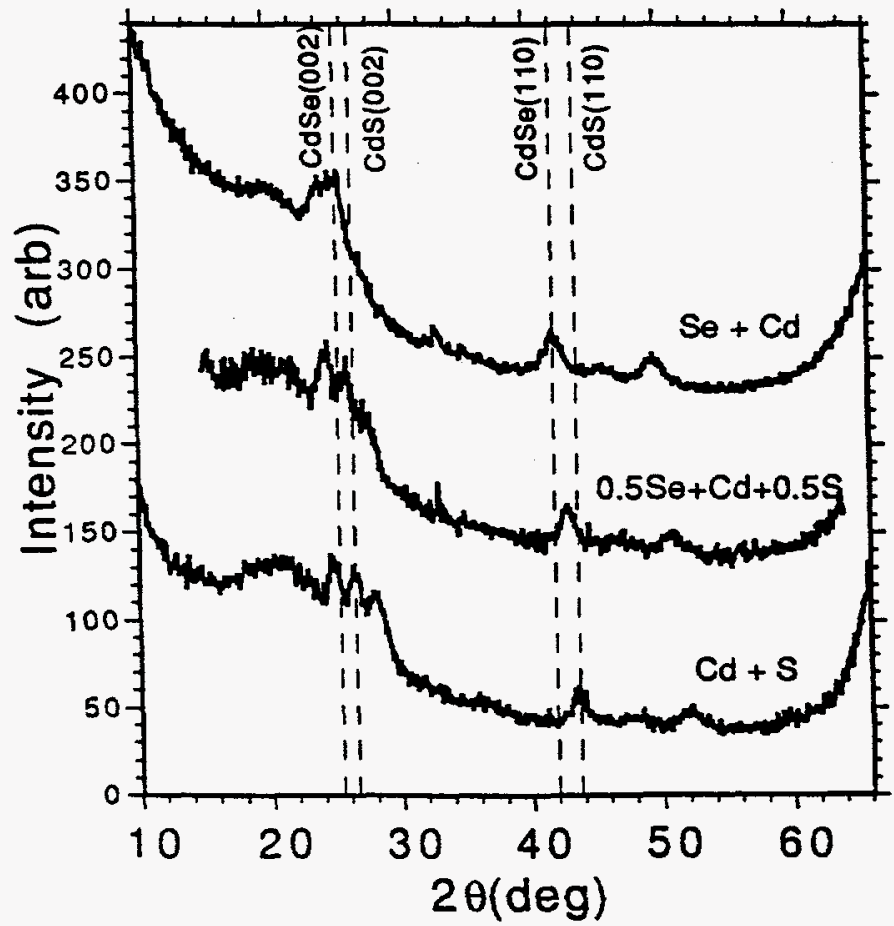

Fig. 7. X-ray diffraction results following the implantation of various combinations of group II and group VI ions. Energies were chosen to give an overlap of the profiles. Equal doses $\left(1 \times 10^{17} / \mathrm{cm}^{2}\right)$ were used for the group II and group VI ions. Implanted samples were annealed at $1000^{\circ} \mathrm{C} / 1 \mathrm{~h}$.
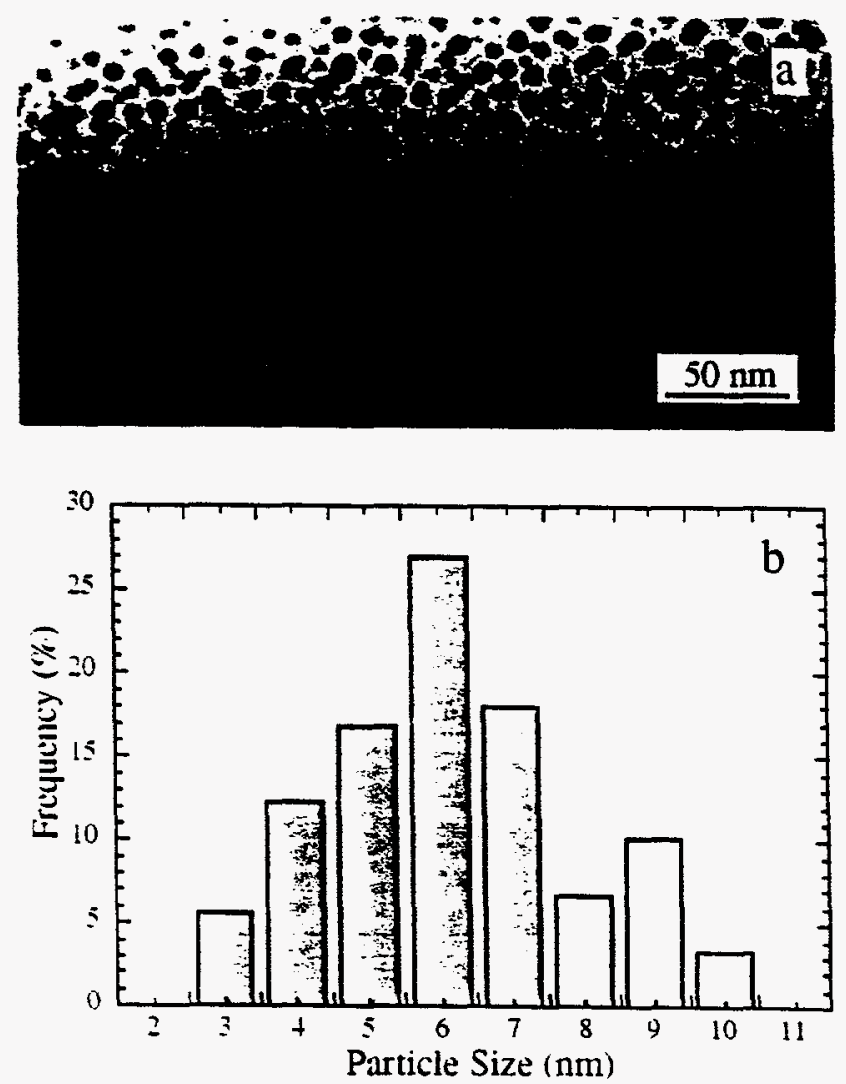

Fig. 8a. Cross section micrograph showing CdSe nanocrystals in $\mathrm{SiO}_{2}$. Implanted samples were annealed at $1000^{\circ} \mathrm{C} / 1 \mathrm{~h}$. Fig. 8b. Measured size distribution for $\mathrm{CdSe}$ nanocrystals shown in Fig. 8a. 


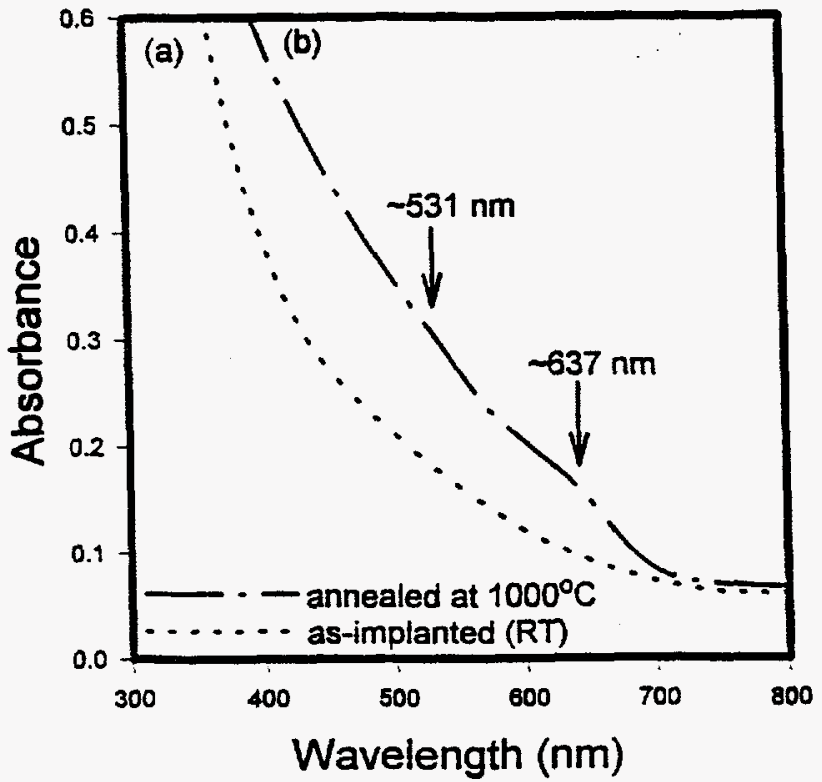

Fig. 9. Optical absorption due to $\mathrm{CdSe}$ nanocrystals in $\mathrm{SiO}_{2}$. Equal doses $\left(1 \times 10^{17} / \mathrm{cm}^{2}\right)$ were implanted and samples were annealed at $1000^{\circ} \mathrm{C} / 1 \mathrm{~h}$.
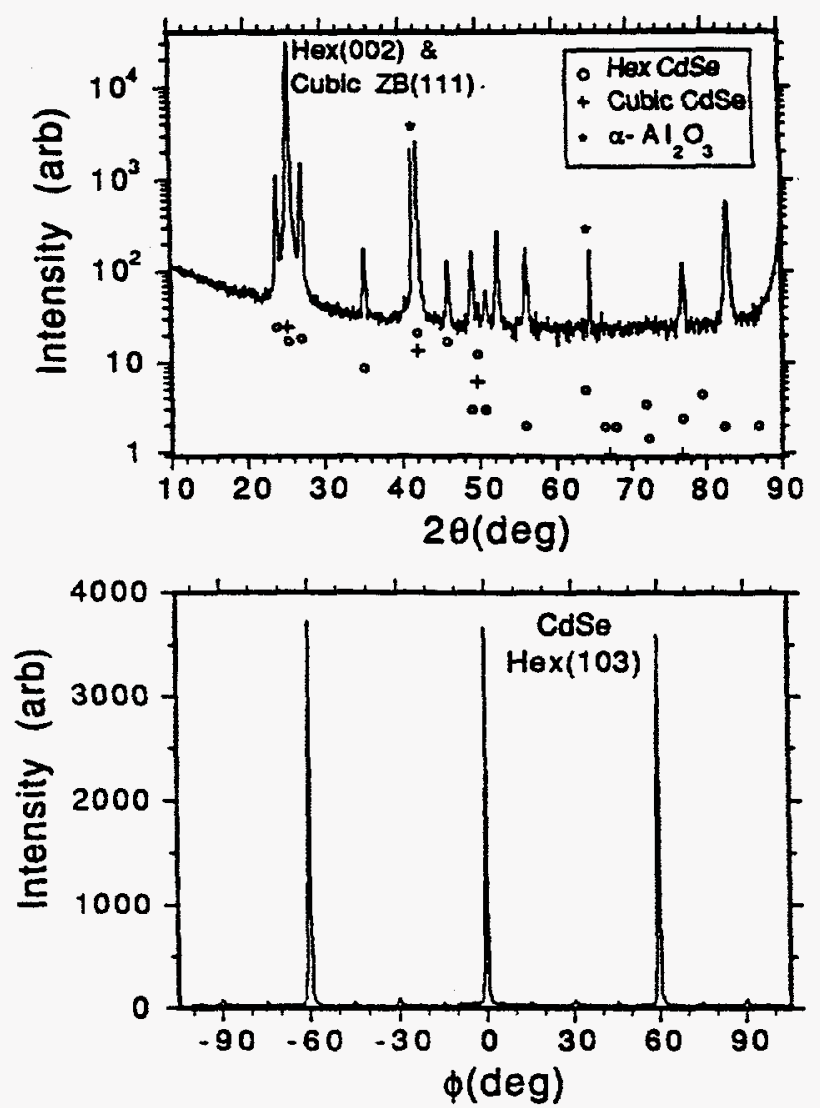

Fig. 10. X-ray diffraction from $\mathrm{CdSe}$ nanocrystals in $\alpha-\mathrm{Al}_{2} \mathrm{O}_{3}$. Equal doses $\left(4.3 \times 10^{16} / \mathrm{cm}^{2}\right)$ of $\mathrm{Cd}(450 \mathrm{keV})$ and Se $(330 \mathrm{keV})$ were implanted at a substrate temperature of $600^{\circ} \mathrm{C}$. This sample was annealed at $1000^{\circ} \mathrm{C} / 1 \mathrm{~h} . \theta-2 \theta$ scans along the $\mathrm{Al}_{2} \mathrm{O}_{3} \mathrm{c}$ axis are shown at the top. $\phi$ scans through the 103 reflection for the (002) oriented hexagonal CdSe nanocrystals are shown in the bottom panel.

Fig. 11. PL from hexagonal CdSe nanocrystals in $\mathrm{Al}_{2} \mathrm{O}_{3}$ compared to that from a CdSe standard. Photoexcitation at $514.5 \mathrm{~nm}$ was used in each case. The intensity from the standard has been divided by a factor of 5 for purposes of comparison. 
Table I. Nanocrystal compounds formed by sequential implantation.

An $\mathrm{x}$ indicates that the compound was formed in the given matrix.

\begin{tabular}{|l|c|c|c|}
\hline \multirow{2}{*}{ Nanocrystal } & \multicolumn{3}{|c|}{ Substrate } \\
\cline { 2 - 4 } & $\mathrm{SiO}_{2}$ & $\mathrm{Al}_{2} \mathrm{O}_{3}$ & $\mathrm{Si}$ \\
\hline $\mathrm{SiGe}$ & $\mathrm{x}$ & $\mathrm{x}$ & \\
\hline $\mathrm{GaAs}$ & $\mathrm{x}$ & $\mathrm{x}$ & $\mathbf{x}$ \\
\hline $\mathrm{InAs}$ & $\mathrm{x}$ & & $\mathbf{x}$ \\
\hline $\mathrm{GaP}$ & $\mathrm{x}$ & & \\
\hline $\mathrm{InP}$ & $\mathrm{x}$ & $\mathrm{x}$ & \\
\hline $\mathrm{CdS}$ & $\mathrm{x}$ & $\mathrm{x}$ & \\
\hline $\mathrm{CdSe}$ & $\mathrm{x}$ & & \\
\hline $\mathrm{CdSe} 0.5 \mathrm{~S}_{0.5}$ & & $\mathrm{x}$ & \\
\hline $\mathrm{GaN}$ & & & \\
\hline
\end{tabular}

\section{ACKNOWLEDGMENT}

Oak Ridge National Laboratory, managed by Lockheed Martin Energy Research Corp. for the U.S. Department of Energy under contract number DE-AC05-960R22464.

\section{REFERENCES}

1. See for example R. P. Andres et al., J. Mater. Res. 4, 704 (1989).

2. R. H. Magruder, L. Yang, R. F. Haglund, C. W. White, C. Yang, R. Dorsinville, and R. R. Alfando, Appl. Phys. Lett. 62, 1730 (1993).

3. C. W. White, D. S. Zhou, J. D. Budai, R. A. Zuhr, R. H. Magruder, and D. H. Osborne, Mat. Res. Soc. Symp. Proc. 316, 499 (1994).

4. K. Fukuami, A. Chayahara, M. Satou, J. Hayakawa, M Hangyo, S. Nakashima, Jap. J. Appl. Phys. 30, L742 (1991).

5. R. H. Magruder, R. F. Haglund, L. Yang, J. E. Wittig, and R. A. Zuhr, J. Appl. Phys. 76, 708 (1994).

6. R. F. Haglund, L. Yang, R. H. Magruder, J. E. Wittig, K. Becker, and R. A. Zuhr, Opt. Lett. 18,373 (1993).

7. H. Atwater, K. V. Shcheglov, S. S. Wong, K. J. Vahala, R. C. Flagan, M. L. Brongersma, and A. Polman, Mat. Res. Soc. Symp. Proc. 316, 409 (1994).

8. H. Takagi, H. Ogawa, Y. Yamazaki, A. Ishizaki, and T. Nakagiri, Appl. Phys. Lett. 56, 2379 (1990).

9. Y. Maeda, N. Tsukamoto, Y. Yazawa, Y. Kanemitsu, and Y. Masumoto, Appl. Phys. Lett. 59, 3168 (1991).

10. T. Shimizu-Iwayama, K. Fujita, S. Nakao, K. Saitoh, T. Fujita, and N. Itoh, J. Appl. Phys. 75, 7779 (1994).

11. J. G. Zhu, C. W. White, J. D. Budai, S. P. Withrow, and Y. Chen, Mat. Res. Soc. Symp. Proc. 358, 175 (1995).

12. J. G. Zhu, C. W. White, J. D. Budai, S. P. Withrow, and Y. Chen, J. Appl. Phys. 78, 4386 (1995).

13. C. W. White, J. D. Budai, S. P. Withrow, S. J. Pennycook, D. M. Hembree, Jr., D. S. Zhou, T. Yo-Dihn, and R. H. Magruder, Mat. Res. Soc. Symp. Proc. 316, 487 (1994). 
14. C. W. White, J. D. Budai, J. G. Zhu, S. P. Withrow, R. A. Zuhr, Y. Chen, D. M. Hembree, Jr., R. H. Magruder, and D. O. Henderson, Mat. Res. Soc. Symp. Proc. 358, 169 (1995).

15. R. H. Magruder, J. E. Wittig, and R. A. Zuhr, J. Non. Cryst. Solids 163, 162 (1993).

16. R. K. Jain and R. C. Lind, J. Opt. Soc. Am. 73, 647 (1983).

17. F. Hache, D. Ricard, C. Flyzanis, and U. Kreibig, Appl. Phys. A47, 347 (1988).

18. C. W. White, J. D. Budai, J. G. Zhu, S. P. Withrow, R. A. Zuhr, D. M. Hembree, D. O. Henderson, A. Ueda, Y. S. Tung, and R. Mu, Journal of Applied Physics (in press).

19. C. W. White, J. D. Budai, J. G. Zhu, S. P. Withrow, and M. J. Aziz, submitted to Applied Physics Letters. 